\title{
Ceticismo de Hume através do Empirismo Transcendental de Deleuze: disjunção inclusiva e sujeito empírico
}

Hélio Rebello Cardoso Júnior

Universidade Estadual de Londrina

herebell@uel.br

resumo 0 presente artigo se inic ia com uma cláusula interna à filosof ia deleuzeana, a de que todo pensamento pode ser carcterizado pelo grau de imanência que o mesmo realiza. 0 pensamento de Hume, como "empirismo superior", segundo expressão de Deleuze, pro moveria a iman ência, ou seja, ele não se re nde riaa ne n hum trans cendente. Ao mesmo tempo, comosuperior, se trata de um empirismo que não se prende ao ime $d$ ia tamente dado, como suporia um "empirismoing ênuo". Por isso, o empirismo seria um pensamento da imanência que apresenta certa alçada transcendental, permitindo a Deleuze falar em "empirismo transcendental". A complexa fórmula filosófica resumida nessa expressão deleuzeana será por nós, aqui, tratada sob o ponto de vista Hume, de mo do que o ceticismo humeano será tomado como um operador de imanência que oferece ao empirismo sua dimensão transcendental. Tal tratamento será levado a cabo em duas etapas, quais sejam: a) ceticismo e problema da disjunção inclusiva na interação das faculdades (razão/entendimento e faculdade prática); b) ceticismo e transcendentalida de dos juízos empíric os.

palavras-chave Ceticismo; Empirismo; Hume; Deleuze; Transcendental; Imanência

\section{Posição do problema}

Deleuze sempre declarou sua proximidade para com o pensamento empirista. Afirmemos, para começar, que todo recurso que sua filosofia fará ao empirismo, estará vinculada a Hume, pensador a quem dedica seu primeiro livro, Empirismo e Subjetividade (DELEUZE, 19531), num 


\section{2}

momento em que a maior parte da filosofia francesa fazia sua conversão fenomenológica ou afirmava o estruturalismo.

Hume proporia um "empirismo superior" ou "radical", conforme denomina Deleuze, onde a ênfase deve recair sobre a relação entre os dados, e não sobre os dados sensíveis por si mesmos, como requereria, por sua vez, um "empirismo ingênuo" - ou "um racionalismo às avessas" pois, apesar da história da filosofia ter feito do "empirismo uma crítica do inatismo, do a priori", ele "sempre teve outros segredos", visto que é um "estudo da legitimidade das práticas nesse mundo empírico que é, de fato, o nosso" (DELEUZE, 1974, p. 59). De outro lado, as bases filosóficas desse empirismo superior seriam mobilizadas por uma filosofia da imanência pura, pois a "imanência implica uma pura ontologia, uma teoria do Ser" (DELEUZE, 1968a, p. 157) e um plano de "PensamentoNatureza é sempre imanente" (DELEUZE \& GUATTARI, 1991, p. 85). De fato, quando a imanência do pensamento atinge sua plenitude "é talvez um empirismo radical", asseveram Deleuze e Guattari (DELEUZE \& GUATTARI, 1991, p. 49). Temos então que um empirismo guiado por princípios imanentes, constitui-se em uma importante passagem da filosofia deleuzeana.

Contudo, ao averiguar associação entre empirismo e imanência no pensamento de Deleuze (CARDOSO JR., 2005), percebemos que a cláusula de imanência não exclui critérios transcendentais, embora a alçada destes destoe seja do transcendental kantiano seja do husserliano ${ }^{2}$. Tanto é assim, que Deleuze virá nos surpreender com a denominação heterodoxa de "empirismo transcendental"3. Expressão esta que se refere, em primeira instância, ao empirismo de Hume, cujo caráter superior,então, estaria garantido pela chancela do transcendental. Além disso, o empirismo transcendental pode ser observado em outras filosofias que, embora não partam do empirismo como solo filosófico, acabam por criar com ele ressonâncias que desafiam as linhagens estabelecidas pela história da filosofia, como no caso de Nietzsche (DELEUZE, 1977, p. 4, 10, 56). Essa hibridação não faz de Hume um nietzscheano nem de Nietzsche um empirista, apenas assinala que ambos lançam, de parte a parte, problemas filosóficos que ecoam entre si, apesar de que suas resoluções sejam diversas em cada caso.

Contudo, se é uma tarefa conseqüente definir o empirismo como filosofia da imanência, pretendemos, aqui, especificar e delimitar essa 
cláusula a fim de saber que tipo de transcendental é apropriado ao empirismo de Hume, pois, naturalmente, esta tarefa envolve um enfrentamento com o pensamento transcendental de Kant. Esse objetivo nos proporcionará, em contrapartida, um percurso, talvez, inesperado, através do pensamento de Hume, uma vez que seremos embalados pela tese deleuzeana - cumpre repetir - de que o empirismo é uma filosofia da imanência e, por isso, a justo título, pode receber sua credencial como pensamento em que se efetiva um tipo específico de transcendental. Dentro desse escopo maior, a hipótese lançada no decorrer do presente artigo é a de que o ceticismo humeano é um operador de imanência que oferece ao empirismo sua dimensão transcendental.

A abdução de tal proposição, no sentido que confere Peirce a tal expressão, isto é, como hipótese que "inclui algo de novo"4 (PEIRCE, 1935, 5.172) que diz respeito a nossos hábitos de pensar, será conduzida em duas etapas. Na primeira parte, trataremos da questão do ceticismo quanto à interação das faculdades (razão/entendimento e faculdade prática), em três registros: a razão que se engaja em processos práticos e a derivação do entendimento; o efeito da interação entre faculdades como sujeito cético e o caráter disjuntivo de sua identidade; o ceticismo e a parcialidade do objeto quanto ao sistema moral/prático. Numa segunda parte, abordaremos o ceticismo como definidor de um novo caráter para as sínteses e os juízos do pensamento, de modo que estes justificariam e qualificariam uma imagem do empirismo como transcendental; isto, em dois registros: a transcendentalidade das sínteses empíricas; e a defecção do empirismo transcendental para com a imagem transcendental do pensamento em Kant.

\section{PARTE - Ceticismo das faculdades e da subjetividade}

a) ceticismo de uma razão engajada em processos práticos e caráter derivativo do entendimento

Um pensamento imanente como o empirismo propõe uma expressão singular do entendimento e da razão, bem como de suas relações mútuas, ao levar em conta uma verdadeira atividade prática.

Quanto a este objetivo, cabe afirmar, de saída, que Deleuze abole a teoria das faculdades com base na harmonia do senso comum kantiano, 


\section{4}

mas não deixa de propor uma nova idéia do relacionamento entre elas, desta vez baseada em um "acordo discordante" ou disjuntivo. Segundo a perspectiva deleuzeana, o acordo entre as faculdades não se realiza sem que se estabeleça entre elas certa disjuntividade. Deleuze trata extensamente da questão da "disjunção inclusiva", demonstrando que a mesma tomava parte na definição de um princípio ontológico, onde se discutia o seu desempenho do ponto de vista do acordo kantiano das faculdades (cf. DELEUZE, 1963, p. 14, 31-32, 44-46, 62-63 e 103-104). Ademais, a disjuntividade fora incluída como patrocinadora de uma nova definição do senso comum que se suprimia ao acordo transcendental das faculdades, do ponto de vista husserliano (cf. DELEUZE, 1969, p. 119 e ss.).

Mas, o que a disjuntividade tem a ver com o ceticismo e o empirismo?

Ora, no quadro deleuzeano das faculdades, define-se um tipo de prática que mais se expõe à abertura do encontro e da experimentação. E, por conseguinte, precisamos saber se não teria ela a função de deslocar as demais faculdades, delas exigindo um acordo discordante, que, enfim, dissemina um modo de experimentação como base de uma pragmática das faculdades (cf. MACHADO, 1990, p. 142-145)5 .

O tratamento desta questão nos leva incontinente a revisitar, em alguns pontos precisos, um dos traços manifestos do pensamento de Deleuze: sua queda pelo empirismo de Hume, pois é nesse pensamento aliado, na sua interseção com a filosofia deleuzeana, que podemos encontrar a prática como fator de disjunção do sistema entendimento/razão, de tal forma que razão e entendimento são faculdades redefinidas de um modo empirista.Veremos, para sermos mais precisos, que a disjunção inclusiva deleuzeana pode ser tomada como operador do ceticismo humeano.

O pensamento não pode ser cindido em teoria e prática, nem mesmo por um roteador transcendental que distribui limites e competências. Essa cisão não é possível para o sistema do entendimento/razão e o sistema da moral, visto que há, ligando a ambos, segundo Deleuze, uma "prática do entendimento" bem como uma "teoria da moral". Observa-se um paralelismo entre a "crença" do entendimento e a "simpatia" da moral. D eve haver, portanto, certa ressonância entre entendimento e moral que forneça a esses sistemas uma determinada maneira de realizar o encontro entre os respectivos âmbitos. Por isso, Deleuze pode afirmar que "em todo caso, em Hume, a única teoria 
possível é uma teoria da prática" (DELEUZE, 1953, p. 17) ${ }^{6}$. Tal lição haverá de incluir um desdobramento cético.

O “empirismo superior", que é o nome pelo qual Deleuze qualifica e homenageia a filosofia de Hume, se caracteriza, antes de tudo, por uma "teoria da prática". E a teoria da prática contém um acordo discordante das faculdades, pois integra essencialmente questões de ordem ontológi$\mathrm{ca}^{7}$. A teoria da prática, por sua vez, sendo um dos substratos desse "empirismo superior", é por isso mesmo, conforme Deleuze, um operador da imanência, já que se aplica a uma "vida" que "escapa a toda transcendência do sujeito assim como do objeto" (DELEUZE, 1995, p. 4). Na teoria da prática, o ponto de partida é conferido a razão, vejamos.

Ao se referir à filosofia humeana, Deleuze demonstra que a principal característica da "teoria de uma prática", é que entre a razão e a prática se estabelece um jogo que, se por um lado, realiza certa disjunção, por outro, permite uma relação de criação. Disjuntivamente, a razão informa a existência de alguma coisa para que se possa agir, influindo na prática, mas não é ela que determina a ação. $\mathrm{Na}$ verdade, se formos acompanhar com certa acuidade os meandros de um argumento humeano a este respeito, veremos que a razão secunda a prática através de juízos que acompanham a ação e que podem ser de dois tipos. Ou são juízos que dizem respeito à presença de um objeto que interessa a uma determinada ação, porque supostamente é fonte de prazer ou dor. Ou são juízos que dizem respeito à série de causas e efeitos que decorrem de uma ação perpetrada. Nestes casos, os tipos de juízos podem ser verdadeiros ou falsos, e por isso "podese dizer que eles produzem-nas [as ações] em certo sentido" (HUME, 1978, p. 159) $)^{8}$ mas esse é "um modo de falar figurado e impróprio" (HUME, 1978, p. 159), considera Hume.

Em todo caso, a prática é exterior à razão, por isso a esta é permitida uma reflexão pragmática onde não está pressuposta sua coextensividade ao ser e a tudo que é, como, por exemplo, no sistema kantiano. A exterioridade da prática com relação à razão é importante, em primeiro lugar, porque a razão já não precisa praticar certo contorcionismo para fundamentar seus juízos, em uma dialética transcendental em que ela própria figura como o fator que deve provar-se como fundamento. E , em segundo lugar, p o rque a partir daí instaura-se uma relação original entre o sistema do entendimento/razão e o sistema moral. 


\section{6}

Com efeito, o entendimento surge como uma espécie de derivado da exterioridade e da indiferença da prática com relação à razão. Hume denomina este elemento de "ceticismo com respeito à razão", em que, "sempre temos de corrigir o primeiro juízo, derivado da natureza do objeto, por um outro juízo, derivado da natureza do entendimento" (HUME, 1978, p. 182)9. Mas, este segundo juízo, já tocado pela incerteza do primeiro, será corrigido, por sua vez, pelo entendimento na tentativa atribuir a ele mais certeza e, assim por diante, ao infinito. A cada vez que o entendimento acresce um juízo à série, mais a certeza se enfraquece, à medida que este se afasta da "natureza do objeto", que resta indiferente em sua exterioridade (HUME, 1978, p. 180-185) ${ }^{10}$.

A razão não se torna inerte quanto à exterioridade que lhe impinge a prática. Ela interioriza e reflete essa exterioridade como seu ceticismo, de modo que um "positivismo da moral", ou seja, a afirmação de sua exterioridade ou indiferença com relação ao âmbito da razão, transforma-se em um "positivismo do entendimento", segundo expressões de Deleuze. Um se constitui à imagem do outro, porém não há regras transcendentais para que a razão torne-se o fundamento de ambos os sistemas.

A ausência do acordo transcendental gera aparentemente um círculo vicioso pois, se um positivismo do entendimento se forma à imagem de um positivismo da moral, isto não anula o fato de que a prática, sendo indiferente à razão, também deve sê-lo em relação ao próprio ceticismo da razão que engendrara o sistema do entendimento (cf. DELEUZE, 1953, p. 16-19, 139-142)11.

Em que pese este círculo, como veremos desfazer-se adiante, pode-se afirmar, por ora, a partir dos elementos disponíveis, que a partir dele o conjunto das faculdades pode constituir um elo disjuntivo ou cético, isto é, a razão é um processo que se inicia quando, sob as pressões de uma prática indiferente, secreta-se o sistema do entendimento. A razão nunca é totalizadora, mas processual, ela é composta por racionalidades múltiplas que se engajam na singularidade das situações práticas. $\mathrm{O}$ entendimento emerge como solução para as circunstâncias em que a indiferença do objeto da prática surpreende a razão.

De acordo com o curso de nosso argumento a respeito da indiferença da prática, perecebemos que razão ou entendimento, de um modo geral, dever ser entendido como uma potência da natureza humana, diversa da 
potência prática, e sujeita à indiferença ou ceticismo desta última. Não obstante, de um modo específico, razão e entendimento são faculdades como resultado do jogo de indiferença entre ambas as potências, e na medida em que se dá o relacionamento entre sistema do entendimento e sistema moral. O entendimento, cujo caráter é derivativo, como dizíamos, e por isso a princípio parece deficitário em poder com relação à razão, no entanto, terá uma função singular na mediação entre a razão e sistema moral que regula a prática. É essa derivação empirista que teremos de averiguar com o auxílio de Deleuze, em algumas de suas decorrências.

b) sujeito empírico e ceticismo: caráter disjuntivo da identidade Ora, o que vai nos interessar na teoria da prática, em primeiro lugar, é que nela encontramos uma redefinição da função da subjetividade. Já que pode-se perguntar - o que faz um sujeito entre a indiferença da prática, o ceticismo da razão e o caráter derivativo do entendimento? (cf. DANOWSKI, 2000, P. 195-198) ${ }^{12}$. Essa redefinição cética deve estar na base do empirismo, uma vez que a identidade que atri buímos à subjetiv idade ou "mente humana, é apenas uma ficção e do mesmo tipo daquela que atri buímos aos animais ou plantas" (HUME, 1978, p. 259)13, afirma Hume. A ficção da identidade se dá porque é uma relação que está baseada em impressões ou percepções, de modo que a mais unitária das subjetividades não poderia fazer com que estas últimas "percam seu caráter de distinção e diferença, que é essencial para elas. É verdade ainda que toda percepção distinta, que entra na composição da mente, é uma existência distinta, e é diferente, seja ela contemporânea ou sucessiva" (HUME, 1978, p. 259), de modo que a relação entre elas "somente pode fazer surgir alguma ficção ou princípio imaginário de união" (HUME, 1978, p. 269) ${ }^{14}$.

Quanto a este aspecto, trata-se para nós de saber que a função de subjetividade, fantasiosa e suposta, coaduna-se com o descentramento cético característico do acordo disjuntivo das faculdades. Precisamos, então, demonstrar agora a disjuntividade do acordo entre as faculdades do ponto de vista da experimentação de um sujeito empírico.

Mas qual a operação filosófica que garante esse objetivo?

Já vimos que o pensamento, segundo Deleuze, alicerçando-se em uma teoria da prática de perfil empirista, observa que nenhum fator, 
nem mesmo a razão, poderia violar o campo de imanência dasmultiplicidades, dotando-as de um fundamento. A razão, p e rdendo o lugar de fundamento do sistema do entendimento e do sistema moral, deixa de ser igualmente o alicerce para uma subjetividade que desfrutaria de prerrogativas originárias ou transcendentais. O sujeito já não é um dado com que temos de lidar, de modo que a análise das condições de sua constituição não mais se limita à especificação das operações especulativas ou práticas que ele preside. O sujeito é um resultado, ele é o conjunto de efeitos dos "princípios de associação" do entendimento e dos "princípios da moral”, sendo esta tese central de Deleuze no liv ro Hume: empirismo e subjetividade.

Em consonância, afirma Hume, a subjetividade provém da concorrência de dois tipos de "identidade" que se enxertam mutuamente, uma vez que "precisamos fazer a distinção entre identidade pessoal com respeito a nosso pensamento ou imaginação e com respeito com nossas paixões ou interesse relativo a nós mesmos" (HUME, 1978, p. 253)15. Trata-se de uma identidade especulativa (do entendimento) e de uma identidade da moral. A fonte de ambas as acepções é a mesma, posto que, observa Hume, o ponto de partida do sistema moral é o mesmo que o do sistema do entendimento, isto é, para se julgar se uma ação é boa ou má, tem-se de partir de "percepções" (impressões ou idéias) (HUME, 1978, p. 456) ${ }^{16}$. Contudo, para o sistema do entendimento, a identidade depende de uma associação de idéias; ao passo que, para o sistema moral, ela é uma relação entre idéias gerada por um interesse prático ou paixão, a exemplo do que acontece com o orgulho (HUME, 1978, p. 286-287) ${ }^{17}$. A subjetividade, portanto, não é princípio, mas efeito, não está associada a nenhum fundamento, pois deriva de um campo de percepções organizado por dois princípios diversos.

$\mathrm{O}$ aludido círculo vicioso de um eterno desencontro entre o ceticismo da razão e a indiferença da prática, de que falamos um pouca acima, resolve-se nessa acepção da subjetividade. A subjetividade não é apriorística, já que não antecede à experimentação e constitui-se após os princípios. Ela não pode desfrutar do caráter transcendental da razão, pois deriva da experiência. A unidade subjetiva forma-se, exatamente, quando se dá o envolvimento entre os princípios de associação e os princípios da moral, os quais operam em paralelo, posto que, afirma Hume, entre 
"motivos, desejos e ações" há a mesma "união" e a mesma "necessidade" que entre dois objetos físicos dos quais um é a causa do outro, embora derivem de princípios diversos (cf. HUME, 1978, p. 399-407) ${ }^{18}$. Em suma, sendo a disjuntividade geradora de um círculo, este se desfaz quando, do ponto de vista da síntese das percepções, o ceticismo se desdobra produtivamente tendo como resultado um sujeito empírico.

Mas como a subjetividade se constitui, to reendo-se na disjunção de ambos os princípios?

A relação entre os princípios da moral e os princípios do entendimento depende da necessidade que ambos desfrutam em comum. Hume precisa essa noção de a fim de desmentir aqueles que põem palavras em sua boca, ao dizerem que

atribuo necessidade às ações humanas e as coloco no mesmo nível que as operações da matéria insensível. Não atribuo à vontade aquela necessidade ininteligível, que se supõe estar contida na matéria. Mas eu atribuo à matéria aquela necessidade inteligível, seja ela denominada necessidade ou não, que o mais ortodoxo admitirá ou terá de admitir que pertence à vontade. Em nada altero, com isso, os sistemas herdados, com respeito à vontade, mas somente com respeito aos objetos materiais (HUME, 1978, p. 410; grifos meus) ${ }^{19}$.

E tal envolvimento entre a moral e o entendimento, do ponto de vista da necessidade, resolve-se através de um paradoxo disjuntivo, qual seja, uma regra geral deste último (o entendimento) somente serve à primeira quando a moral confirma na ação uma exceção àquela mesma regra. Quer dizer, uma idéia só serve à prática quando se adequa a uma atividade que esteja indicando uma associação entre dados que expurga o alcance de uma regra do entendimento até então vigente. Ora, como dizíamos, a indiferença da prática com relação à razão gera um ceticismo desta, cuja reflexão se constitui através de um sistema do entendimento, e cujas regras são móveis e constantemente deslocadas em função da constituição de um sistema moral. Sendo assim, a associação de idéias não é uma mera teoria do conhecimento, mas do que é prático. Há uma prática da moral assim como uma prática do entendimento.

Sigamos na demonstração dessa disjuntividade contida na teoria da prática sob os auspícios de um sujeito empírico cuja identidade participa 
ou, ainda, se constitui, também, disjuntivamente - ceticamente, digamos, para fazer valer o ponto nodal de nosso argumento no presente artigo.

c) princípios da moral e ceticismo: parcialidade do objeto Consequentemente, apresentemos uma demonstração correlata para a constituição da subjetividade como imbricação de entendimento e moral, tendo em vista, a partir de agora, os tipos de dados a partir dos quais o sujeito deriva, seja quanto à prática do entendimento seja quanto à da moral. Novamente, ve remos como o problema do ceticismo da razão, entendido no contexto deleuzeano como aplicação de um princípio de disjuntividade, realiza a imbricação do pensamento de Deleuze com o empirismo superior de Hume.

É uma indagação básica para Hume saber se a razão é suficiente para fazer a distinção entre o bem ou o mal ou se tal distinção é tributária de outros princípios, ou seja, de uma regência diversa sobre as percepções que o entendimento utiliza a seu modo,

visto que a moralidade tem influência sobre ações e afecções, segue-se que ela não pode ser derivada da razão; e que a razão por si mesma, como já comprovamos, jamais poder ter tal influência. A moralidade motiva paixões, e produz ou inibe ações. A razão por si mesma é completamente impotente neste particular. As regras da moralidade, por isso, não decorrem da razão (HUME, 1978, p. 457) ${ }^{20}$.

$\mathrm{Na}$ prática do entendimento, trata-se de aplicar regras gerais que estejam de acordo com os princípios de associação que conhecemos através da natureza. Já na prática da moral, o sujeito empírico lida com dados tomados em sua imediatidade, isto é, que não fornecem inferências de associações. Ele precisa, então, não mais aplicar regras gerais a fim de ultrapassar o dado, mas inventá-las, de modo a integrar a diversidade e singularidade dos dados, respeitando a sua parcialidade ou sua diferença, como mostrou Deleuze (cf. DELEUZE, 1953, p. 20-22, 90-92, 116-117, 137, 151-152). Contudo, o relacionamento entre uma associação natural e uma regra moral é sempre problemático, visto que a parcialidade do móvel moral (objeto) de uma ação é sempre excessiva tendo em vista uma determinada regra geral do entendimento, obrigando-a a refletir-se como criação de uma regra geral no domínio da moral, como se observou acima. 
Ambas as regras gerais conectam-se, diferenciando-se, porque, diz Hume, um [entendimento] descobre os objetos como eles realmente se apresentam na natureza, sem adição nem diminuição: a outra [moral] tem uma faculdade produtiva, e enfeitando ou tingindo todos os objetos naturais com as cores emprestadas ao sentimento interno, ocasiona, de um certo modo, uma nova criação (HUME, 1998, p. 163)21

Por isso, há certa divergência na formação do sujeito, seja em um caso seja em outro. De fato, no empirismo, o sujeito, nos informa Deleuze, constitui-se ao mesmo tempo em que se forma um sistema a partir da coleção de objetos/percepções dos dados. Seja ele um sistema onde a coleção é tomada a partir do ponto de vista genérico dos objetos da natureza (sistema do entendimento), seja ele um sistema em que a coleção é vista em termos do destaque dado à parcialidade ou imediatidade de um de seus objetos (sistema moral). Para o sistema do entendimento vale, mostra Hume, a "descoberta da veracidade ou falsidade", pois as idéias ou evidências são tomadas associativa ou comparativamente e, por isso, podem estar em "concordância ou discordância" umas com relação às outras. Já, continı Hume, quanto às nossas "paixões, desejos e ações" não se pode dizer que sejam verdadeiros ou falsos, nem que sejam racionais ou irracionais, pois são "fatos originais e realidades, completos em si mesmos", e não implicam " referência a outras paixões, desejos e ações" (HUME, 1978, p. 459)22.

Já que tratamos, até este ponto, da gênese do sujeito empírico como efeito de sínteses empíricas diferentemente aplicadas sobre dados, vejamos em seguida que tipos de juízos uma tal subjetividade está apta a emitir.

\section{Parte: Ceticismo dos juizos/das sinteses e imagem do empirismo transcendental}

a) transcendentalidade das sínteses a posteriori (do entendimento e da prática) e "circunstância"

Segundo Deleuze, um "ponto de vista comum a todos os empiristas" é o de que as "relações são exteriores às idéias" ou aos termos relacionados (DELEUZE, 1953, p. 109). Sendo assim, podemos dizer que os empiris- 
tas propõem, como um dos traços distintivos de seu pensamento, uma teoria das relações. Particularmente, Hume criou a "primeira grande lógica das relações", declara Deleuze (DELEUZE, 1977, p. x) e com ela se processa "algo muito estranho, que desloca completamente o empirismo", pois a teoria das relações se desenvolve como uma "prática das relações", conferindo ao pensamento empirista um poder genuíno (DELEUZE, 1977, p. 15).

Contudo, como o problema das relações entra na questão do ceticismo que, como estamos indicando, é um traço de ressonância para o empirismo transcendental de Deleuze e o pensamento de Hume?

$\mathrm{Na}$ busca de certas injunções que concorram para a imagem do pensamento deleuzeano, digamos que da teoria empirista das relações deve decorrer, como corolário do ceticismo, como já se terá sugerido na parte anterior, que a união entre os princípios de associação (entendimento) e de interesse/paixão (moral) se estabelece sob a égide desse último. Neste ponto, cabe observar que, ao esquematizar dessa maneira o pensamento de Hume, Deleuze visa fortalecê-lo frente à incorporação do empirismo pela filosofia transcendental de Kant. Mais precisamente, e seguindo uma orientação de Lebrun, deve-se assinalar que Deleuze procurara relançar o transcendental kantiano, de modo a desobstruir "o encolhimento que a Crítica lhe havia imposto" (LEBRUN, 2000, p. 209)23.

Antes de qualquer coisa, Deleuze demonstra que as relações são exterio res às idéias/objetos. Isso quer dizer que o empirismo de Hume está baseado em relações sintéticas, pois se as relações entre idéias estivessem contidas nas idéias ou nos termos relacionados teríamos apenas juízos analíticos. Por outro lado, a noção de que o princípio de paixão ou de interesse (prático) sobrepuja os princípios de associação (conhecimento), não justifica, como em Kant, a vigência de um pensamento transcendental onde a razão reservaria para si a legislação sobre seu interesse prático, enquanto outorgaria ao entendimento seu interesse especulativo. Contudo, cabe perguntar com Deleuze: a relação pragmática entre prática e entendimento, em sua extração humeana, não reservaria uma nova expressão para o transcendental, um “empirismo transcendental"?

A correlação entre os princípios de associação e os princípios de paixão exige uma nova tábua das sínteses do entendimento e da prática 
onde estará implicado a disjunção ou ceticismo como sua matriz empirista (cf. KANT, 1952a, p. 45-48) ${ }^{24}$. De fato, a classificação dos juízos, segundo uma lógica das relações proposta por Hume e promovida por Deleuze, ganha uma nova configuração, pois se a exterioridade das relações define juízos sintéticos, há que se classificar seu caráter sintético segundo a exterioridade da qual os juízos em questão são tributários. Assim, haveria dois tipos de juízos:

a) os juízos sintéticos do entendimento, que derivam de relações exteriores entre idéias/objetos conformando relações naturais; $\mathrm{e}$

b) os juízos sintéticos práticos, que derivam de relações exteriores entre idéias/objetos conformando relações filosóficas (cf. HUME, 1978, p. 13-14) ${ }^{25}$, isto é, com preeminência de "nossa posição com respeito a objetos externos"26 (HUME, 1978, 464).

Ambos os juízos são sintéticos devidos à exterioridade das relações que ligam seus termos e, igualmente, dependentes da experiência, por isso são juízos sintéticos a posteriori, nunca a priori. Como afirma Hume:

todos os seres do universo, considerados em si mesmos, aparecem

inteiramente soltos e independentes um do outro. Somente através da experiência aprendemos sua influência e conexão; e essa influência jamais pode ser estendida para além da experiência (HUME, 1978, p. 466$)^{27}$.

Particularmente quanto aos "princípios gerais da moral", afirma Hume, quanto à determinação das máximas da ação, "como é uma questão de fato, e não de ciência abstrata, apenas podemos esperar sucesso seguindo o método experimental, e deduzindo as máximas gerais de uma comparação de casos particulares" (HUME, 1998, p. 77) ${ }^{28}$. Contudo, o destaque dos juízos sintéticos a posteriori a presenta a questão adicional de saber se tais juízos sintéticos são transcendentais, isto é, se juízos que derivam da experiência aplicam-se a ela no sentido de servirem como regras.

Ora, como juízos cujos princípios variam com os casos ocorridos, podem ser ao mesmo tempo regras para toda a experiência, e por isso, não para a experiência possivel como garantia transcendental de objetividade das sínteses a priori, como quer Kant (Cf. KANT, 1952a, p. 209-213 e p. $551-560)^{29}$, mas para a experiência real? 


\section{4}

Ora, quanto à transcendentalidade desses juízos, deve-se apelar para o caráter de exterioridade das relações. A exterioridade das relações filosóficas serve como disjuntor das naturais, fazendo-as passar por um deslocamento. Neste caso, estamos seguindo, de modo conseqüente, a idéia inicialmente apresentada de que o ceticismo da razão atua como um receptor da prática e, transmite sua disjuntividade ao entendimento. Por isso, os juízos sintéticos a posteriori são transcendentais no sentido de que a criação de novas relações filosóficas, dependentes da "situação com relação a objetos externos" (juízo prático), na expressão humeana - ou, na terminologia kantiana, "móvel exterior" (KANT, 1952b, p. 84) ${ }^{30}$, capaz de caracterizar uma "faculdade inferior de desejar" determinada por "princípios práticos materiais" (KANT, 1952b, p. 24) 31 - faz valer sobre a experiência a regra transcendental de variabilidade das relações.

Mas, o que faz da variabilidade uma regra transcendental?

A imbricação, no empirismo humeano, entre os princípios de associação (entendimento) e de paixão ou interesse (moral) se fazem sob os auspícios destes. Isso acontece, segundo Deleuze, porque "duas idéias, por mais distantes que sejam, sempre apresentam algum ponto de associação, mas isso não explica porque uma idéia presente se liga a uma certa idéia e não a outra qualquer" (DELEUZE, 1953, p. 114). O que relaciona duas idéias que não se unem imediatamente na imaginação, vale dizer, é uma "circunstância particular" que concerne o princípio de paixão ou interesse, já que, afirma o próprio Hume, "há algumas virtudes que produzem prazer e aprovação por meio de um artifício ou invenção que provém das circunstâncias e necessidades da humanidade" (HUME, 1978, p, 477) ${ }^{32}$. Em suma, diz Deleuze, a circunstância é a "razão suficiente" de toda e qualquer relação, enquanto a associação é "condição geral" de toda relação. A circunstância, portanto, esta na base dos juízos sintéticos a posteriori e garante, para o empirismo transcendental, que o ceticismo das faculdades e do sujeito alcance uma dimensão normativa.

Por um lado, uma circunstância, mais precisamente, não seria um detalhamento de uma situação espaço-temporal dada. Ela é como uma aura de singularidade que se apresenta numa série. Esta última pode ser descrita pelas associações de objetos de acordo com uma consciência formal, mas a circunstância é um signo de que algo está exigindo associação destes objetos em particular e não de outros quaisquer. A circunstân- 
cia não pode ser simplesmente descrita, ela precisa ser remetida a um elemento que está indicando a novidade (cf. DELEUZE \& GUATTARI, 1980, p. 115-117, 130, 141-142, 147).

Por outro lado, uma circunstância indica que algo se passa em um intervalo ou lacuna, podendo ser ela definida como relações que não são dadas pelos próprios dados por elas associados ou comparados, ou seja, são exteri o res ou inovadoras com respeito aos termos interligados. Em contrapartida, os próprios dados, sendo a ocasião de criação de relações inauditas, são por isso mesmo "fragmentos" soltos que não fazem parte de uma totalidade preexistente ou perdida e a ser reencontrada. Entenda-se que a fragmentação não corresponde à desordem, pois os pedaços incluem a exterioridade das relações que os põe em contato. A circunstância é justamente a ligação entre eles através de um todo de relações exteriores aos dados, em perpétua mutação. A "noção de circunstância", na medida em que as "circunstâncias são varáveis que definem nossas paixões", insiste Deleuze, está "no centro da história, ela torna possível uma ciência do particular, uma psicologia diferencial" (DELEUZE, 1953, p. 115), posto que "as relações poderão e deverão ser instauradas, inve ntadas. Se as partes são fragmentos não totalizáveis, pode-se ao menos inventar entre elas relações não-preexistentes, testemunhando um progresso na História, assim como uma evolução na Natureza" (DELEUZE \& GUATTARI, 1993, p. 78).

$\mathrm{Na}$ verdade, segundo Deleuze, se a circunstância indica uma "subordinação da associação à paixão", isto quer dizer que o ser humano apresenta, nele mesmo, uma "finalidade secundária" que prepara o "problema da fina-lidade primária, do acordo da natureza humana com a Natureza" (DELEUZE, 1953, p. 138). Afinal, não é possível que o desígnio da circuns-tância fosse abandonado à simples arbitrariedade dos móveis da natureza humana, era necessário ainda que o interesse geral sobrepujasse o interesse particular em sua parcialidade, tornandose o juízo sintético a posteriori uma regra transcendental. É o sentimento que Hume denomina de "humanidade", isto é, a finalidade segunda a qual cada ser humano tende a inventar uma regra geral através da qual o que é bom ou útil para ele, em particular, se estenda aos outros (Cf. HUME, 1998, p. 145-152). 
b) "empirismo transcendental” em defecção com a "imagem transcendental" do pensamento

Mas, no que a circunstancialidade, que faz o todo das relações exteriores sofrer uma constante variação, influi sobre a alegada transcendentalidade do empirismo?

Ora, estamos aptos a estabelecer o elo entre circunstância e ciência do particular, cujas caracterizações realizamos no item anterior. Acontece que, se toda circunstância é razão suficiente das relações, então, é uma ciência do particular toda teoria (relação natural ou associação entre idéias e relação filosófica ou comparação entre idéias) que possua, também, um princípio prático. É assim, em primeiro lugar, porque, como vimos um pouco acima, não se trata de certa divisão transcendental do sistema da razão, pela qual o interesse prático da razão subvenciona a totalidade do sistema, mas não legisla no domínio transcendental do entendimento. Em segundo lugar, e em decorrência disso, porque a circunstância, razão suficiente de toda relação, ou seja, exterior a toda idéia relacionada, por isso mesmo, não entra em nenhuma série em que podem figurar os objetos das percepções/idéias. A circunstância, pelo contrário, além de furtar-se a toda seriação natural, tem o poder de conectar séries totalmente distantes, do ponto de vista das relações de associação ou naturais.

Assim, o empirismo transcendental, em suas ressonâncias humeanas, situase duplamente em face do sistema kantiano. Por um lado, não há uma divisão sistêmica de domínios segundo interesses da razão como princípio. Por outro, ao invés de constituir uma fraqueza do empirismo, esta suposta deficiência torna possível para o empirismo de Hume, em particular, acentuar uma qualidade transcendental que lhe é própria, na medida em que uma circunstância não pertence a nenhuma série causal (natural), mas não é, igualmente, uma causalidade livre que inaugura uma série causal, no sentido kantiano mais uma vez.

A circunstância é um princípio no sentido em que o empirismo pode ser transcendental, isto é, enquanto ela une duas séries causais que não se associam imediatamente na imaginação ou no espírito (juízo prático). Uma circunstância, enfim, possui caráter transcendental, porque, sendo exterior aos termos ou idéias, relaciona-os, aplicando-se à experiência, mas ela não é a priori, pois provém da experiência real. Com isso temos 
que essa ciência do particular define-se pelo caráter transcendental de que a circunstância desfruta no pensamento empirista.

O empirismo transcendental, então, não tem de prestar contas ao que Deleuze, no sistema kantiano, denominava de imagem transcendental, a qual impedia a realização de uma imagem do pensamento baseada na pura imanência, posto que o transcendental kantiano tinha como caráter decalcar sua imagem dos dados empíricos ou fenômenos que condiciona. Na verdade, o empirismo constitui uma "nova concepção do transcendental", segundo expressão de Orlandi (2000), afinada com a imanência do pensamento. Vejamos este aspecto, recuperando a crítica que Deleuze faz à imagem transcendental presente na Crítica do Razão Pura, tendo em vista que, a exemplo do que faz notar Lebrun, ele alarga a concepção de transcendental justamente ao deslocar a imagem transcendental e o esquematismo desta decorrente (cf. LEBRUN, 2000, p. 221, 227-228).

Kant estabelecera que o entendimento condiciona, através do juízo sintético a priori, o espaço e o tempo fenomênicos. E, segundo expressão de Deleuze, o entendimento é uma "forma de determinação" que condiciona os fenômenos, mas estes não são, por sua vez, uma massa amorfa e indeterminada. Pelo contrário, o espaço e o tempo são as formas puras dos fenômenos. Sendo assim, a relação de condicionamento entre o entendimento e o espaço/tempo se daria entre duas formas, a saber, a "forma da determinação" que possui o primado na relação e a "forma do determinável" que acata a "espontaneidade" transcendental do entendimento, nos mostra Deleuze (DELEUZE, 1986, p. 67-75). Em Kant, portanto, a forma da determinação atua como um princípio que deixa à forma do determinável seu modo espaço-temporal próprio. A relação entre ambas assegura que entre elas o condicionamento não se dá pela identidade. O múltiplo espaço-temporal não copia a forma de determinação. Eis a "diferença transcendental".

Contudo, a diferença ou circunstância, para conduzirmos uma necessária aproximação para com os problemas humeanos cuja discussão está em curso, fica neste caso contida na simples disparidade entre as duas formas. Ela contém apenas um princípio condicionante que vai do entendimento ao espaço-tempo, pois o condicionamento transcendental não permite que a própria diferença torne-se interna à forma da deter- 
minação. Mas, se o princípio condicionante kantiano garante que a forma do determinável seja autônoma, o que consente ao entendimento, em contrapartida, que a aplicação do princípio se dê estritamente sobre o mundo fenomênico?

Entre o entendimento e o fenômeno espaço-temporal figura o esquematismo da imaginação (cf. KANT, 1952a, 79-84) ${ }^{33}$ que chancela a aplicação do princípio, mas ao mesmo tempo solda a forma da determinação e a forma do determinável, legando à diferença transcendental uma fixidez que lhe é peculiar. Do lado do entendimento, o esquematismo garante uma unidade sintética para a diversidade espaço-temporal dos fenômenos. Do lado destes últimos, a forma pura do espaço e do tempo se dá à síntese requerida pelo caráter transcendental do entendimento.

Sendo assim, o esquematismo realiza uma dupla perda ou ajuste recíproco em virtude da síntese do diverso. O caráter transcendental do entendimento somente se ajusta sobre uma dada diversidade empírica da qual foi extirpado seu dinamismo ou diferenciação. A diversidade empírica que não comunica sua violência ao transcendental, faz desse um sintetizador da experiência que, por conseguinte, não se contamina ou não responde ao seu caráter diferenciante. Desse modo, a forma da determinação torna-se condicionante por intermédio de uma imagem decalcada ao espaço-temporal que ajusta o transcendental ao empírico imagem transcendental.

Ora, o empirismo transcendental, justamente, não permite que os princípios que guiam a formação das idéias, isto é, as relações naturais e as relações filosóficas, na medida em que estas se abrem para a potência do circunstancial, do diferenciante, conforme-se a uma imagem decalcada daqueles elementos espaço-temporais que este princípio condiciona. Nos termos deleuzeanos acima empregados, o transcendental não se deixa decalcar pela imagem dos elementos que estão sob sua jurisdição como princípio e, simultaneamente, o princípio transcendental passa a incluir um poder de diferenciação interna que o coloca em contato imanente com o poder de variação dos dados que ele condiciona. Por isso pode-se dizer que, em não havendo uma imagem transcendental (um esquematismo de ajuste) entre o entendimento e os fenômenos, o empirismo transcendental promove uma imagem de pura imanência entre ambos. 


\section{Considerações Finais}

Segundo Deleuze, a teoria das relações envolve o segredo da aplicação dos princípios de associação e dos princípios da moral, mantendo a cláusula de imanência pela qual todo empirista deve zelar. E, por isso, é numa teoria das relações que se apóia o ceticismo caro a um empirismo superior.

Para uma filosofia essencialista, neste caso oposta ao empirismo, uma relação entre dois termos deriva e é determinada pelo ser deles mesmos, ou seja, a relação emana dos termos e pode a eles ser reduzida. Desta perspectiva decorrem algumas posições correlacionadas que, segundo a abordagem deleuzeana, rompem a cláusula ontológica de imanência, a saber:

um termo e suas relações formam uma unidade orgânica, e as relações que interligam dois ou mais termos são necessárias para a identidade de cada um e do todo que eles formam. Isto implica, no mínimo, então, que a relação e a coisa que a possui nunca podem existir de uma maneira diversa daquela determinada pela essência da coisa. E há apenas um pequeno passo daí para a posição ontológica de que todas as coisas estão relacionadas de uma maneira inextricável e necessária, e que esta unidade absoluta de alguma forma transcende a diversidade e as contingências do mundo da experiência empírica (HAYDEN, 1995, p. 285).

Com efeito, o tratamento que aqui foi conferido ao empirismo transcendental, a partir de certo ceticismo que se coaduna com um princípio de disjuntividade, poderia seguir se déssemos atenção particular à lógica empirista das relações.

\footnotetext{
${ }^{1}$ A fim de manter o destaque cronológico, fizemos a referência ao ano da primeira edição de determinado livro de Deleuze, embora a edição efetivamente consultada não tenha sido esta, conforme consta de nossas "referências bibliográficas" colocadas no final deste artigo.

2 A equivalência entre "campo transcendental" e "plano de imanência" é assinalada por ZOURABICHVILI, 1994, p. 45-47; para a definição do "transcendental deleuzeano", ver BUYDENS, 1990, p. 13-15, 17-18.
} 
${ }^{3}$ De fato, Deleuze, em um de seus últimos artigos publicados em vida (cf. DELEUZE, 1995, p. 3-7), estava atento para a precisão do relacionamento entre transcendental eimanência em vista de uma definição do "empirismo transcendental", por isso afirmava que "na falta da consciência, o campo transcendental se definiria como um puro plano de imanência, visto que ele escapa a toda transcendência do sujeito como do objeto" (cf. DELEUZE, 1995, p. 3-4).

4 PEIRCE, 1935, resume: "abdução é processo de formação de uma hipótese explanatória" (PEIRCE, 1935, p. 106); a abdução “apenas sugere algo que pode ser” (PEIRCE, 1935, p. 106).

${ }^{5}$ Esse autor assinala que exatamente os filósofos dos quais Deleuze tem muitas razões para discordar, quais sejam, Platão e Kant, se aliam para permitir que Deleuze constitua sua "teoria das faculdades".

6 Mengue (MENGUE, 1994, p. 42) assinala a importância do empirismo de Hume para Deleuze.

${ }^{7}$ Hardt (HARDT, 1993, p. xiii-xiv) assinala o importante traço que liga "prática" e "ontologia" no pensamento de Gilles Deleuze; para as possíveis objeções althusserianas e fenomenoló gicas à concepção deleuzeana de "teoria da prática”, ver (HARDT, 1993, p. 79, 104-107), onde se encontra a seguinte afirmativa: "assim como disse Espinosa a respeito do corpo, Deleuze poderia dizer que ninguém ainda determinou o que pode a prática" (HARDT, 1993, p. 107). Dias (DIAS, 1995, p. 149), referindo-se ao "vitalismo" do pensamento alegado pelo próprio Deleuze, afirma que "um pensamento ou uma filosofia, por exemplo, já não será uma simples questão de teoria mas de vida, de estilo de vida implicado, ou, se se preferir, o critério da teoria já não será teórico”.

${ }^{8}$ Hume, livro III, parte I, seção I: “distinções morais não são derivadas da razão”; resolvemos manter os intertítulos de Hume, pois eles são precisos e ilustrativos do caminho que estamos fazendo através de seus livros.

9 Livro I, parte IV, seção I: “do ceticismo com respeito à razão”.

10 Livro I, parte IV, seção I: “do ceticismo com respeito à razão”.

11 Observar este comentário em paralelo com Hume (HUME, 1978, p. 180-187): Livro I, parte IV, seção I: "do ceticismo com relação à razão", onde o filósofo descreve o círculo vicioso do argumento cético, mostrando que o esforço que a razão despende para pensar enfraquece a crença nos "sentimentos".

12 De acordo com esta autora, Deleuze é inovador com relação à tradição de estudos humeanos, pois reconstrói a filosofia de Hume "em torno da questão da constituição do sujeito a partir do dado da experiência” (DANOWSKI, 2000, p. 195).

13 Livro I, parte IV, seção VI: “da identidade pessoal”.

14 Livro I, parte IV, seção VI: “da identidade pessoal”.

15 Livro I, parte IV, seção VI: “da identidade pessoal”.

16 Livro III, parte I, seção I: “distinções morais não são derivadas da razão”.

17 Livro II, parte I, seção V: "da influência dessas relações no orgulho e na humildade”.

doispontos, Curitiba, São Carlos, vol. 5, n. 1, p.91-113, abril, 2008 
18 Livro II, parte III, seção I: "da liberdade e da necessidade"; sobre o mesmo assunto ver Hume (HUME, 1952, p. 481-484) “Seção VII: da liberdade e da necessidade”, p a rte I, \$\$68-74.

19 Livro II, parte III, seção II: “continuação do mesmo assunto”.

20 Livro III, parte I, seção I: "distinções morais não são derivadas da razão”; ver também Hume (HUME, 1952, p. 423-318) Livro II, parte III, seção III: "dos motivos que influenciam a vontade", onde Hume demonstra que, ao contrário do que pensa a "maior parte da filosofia moral, antiga e moderna", as paixões não se opõem à razão na determinação da vontade, pois são regidas por diferentes princípios, e por isso não se pode conceder à razão o caráter de princípio preeminente ao qual as paixões devem se subjugar ou com o qual devem estar em conformidade; o mesmo argumento se encontra em Hume (HUME, 1998, p. 157-158) (Apêndice 1: acerca do sentimento moral); o ceticismo, em se tratando da razão e da moralidade, encontra um relativo contrapeso de seu solipsismo na experiência, mas o mesmo não se pode dizer das questões relativas à natureza de Deus e à criação e organização do universo, pois, quanto a elas o raciocínio é suspenso e o ceticismo triunfa, cf. (HUME, 1992, p. 9-24) ("Parte I").

${ }^{21}$ Apêndice 1: acerca do sentimento moral.

22 Livro III, parte I, seção I: “distinções morais não são derivadas da razão”.

${ }^{23}$ Lebrun realiza esta intento demonstrando a importância dos estudos deleuzeanos a respeito do transcendental em Nietzsche, em Nietzsche e a Filosofia (1962), de Maimon e de Kant, em A filosofia crítica de Kant (1964) e em Diferença e repetição (1968), e de Leibniz, em A dobra: Leibniz e o barroco (1988), mas pode-se dizer que o trabalho sobre a noção de transcendental se iniciara em 1953, com o livro de Deleuze dedicado a Hume, Empirismo e subjetividade.

24 "Da distinção entre juízos analíticos e juízos sintéticos".

25 Livro I, pare I, seção V: “das relações”.

${ }^{26}$ Livro III, parte I, seção I: “distinções morais não são derivadas da razão”.

27 Livro III, parte I, seção I: “distinções morais não são derivadas da razão”.

28 Seção 1: dos princípios gerais da moral.

29 “Do princípio supremo de todos os juízos sintéticos” e Kant (KANT, 1952ª p. 551-560)

"Do ideal transcendental (Prototypon transzendentale)".

30 cf. (KANT, 1952b, p. 84-85) "Dos móveis da razão pura prática”.

31 cf. (KANT, 1952b, p. 24-25) “Dos princípios da razão pura prática”, $\$ 3$.

32 Livro III, parte II, seção I: “Justiça é uma virtude natural ou artificial?”.

33 "Do esquematismo dos conceitos puros do entendimento"; correlativamente, Kant (KANT, 1952b, p. 79-84) ("Da típica do julgamento puro prático") observa que o juízo prático a priori utiliza utiliza um esquematismo, mas este não é um "esquema" de aplicação de uma lei da natureza à experiência possível, mas um esquema da própria lei moral, de modo que deve chamar-se "tipo" e sua finalidade é a de evitar o "empirismo da razão prática".

doispontos, Curitiba, São Carlos, vol. 5, n. 1, p.91-113, abril, 2008 


\section{Referências bibliográficas}

BUYDENS, M. 1990. Sahara: L'Esthétique de Gilles Deleuze. Paris:Vrin.

CARDOSO JR., H. 2005. Pragmática Menor: Deleuze, imanência e empirismo, 2v.Assis/SP. 571 pp. Tese de Livre-Docência em Filosofia. Universidade Estadual "Júlio de Mesquita Filho" (UNESP).

DANOWSKI, D. 2000. Deleuze sobre Hume, in: ALLIEZ, É. (org).

Gilles Deleuze: uma vida filosófica. São Paulo, Ed. 34.

DELEUZE, G. 1953. Empirisme et Subjectivité. Paris: PUF.

DELEUZE, Gilles. 1962. Nietzsche et la Philosophie, 5e éd. Paris: PUF, 1977.

DELEUZE, G. 1963. La Philosophie Critique de Kant, 5e éd. Paris: PUF, 1983.

DELEUZE, G. 1968a. Spinoza et le Problème de l'Expression. Paris: Minuit.

DELEUZE, G. 1969. Logique du Sens. Paris: Minuit.

DELEUZE, G. 1974. Hume, in Châtelet, F. (dir.). História da Filosofia: idéias, doutrinas, vol. 4. Rio de Janeiro: Zahar.

DELEUZE, G. 1995. L'Immanence: Une Vie..., Philosophie, Minuit, ${ }^{\circ}$ 47 , septembre.

DELEUZE, G. \& GUATTARI, F. 1980. Capitalisme et Schizophrénie: Mille Plateaux. Paris: Minuit.

DELEUZE G. \& GUATTARI, F. 1991. Qu'Est-Ce Que La Philosophie? Paris: Minuit.

DELEUZE, G. \& PARNET, C. 1977. Dialogues. Paris: Flammarion.

DIAS, S. 1995. Lógica do Acontecimento: Deleuze e a Filosofia. Porto: Afrontamento.

HARDT, M. 1993. Gilles Deleuze: An Apprenticeship in Philosophy. University of Minnesota Press.

HAYDEN, P. 1995. From relations to practice in the empiricism of 
Gilles Deleuze, Man and World, University of Hampshire, 283-302, vol. $28, n^{\circ} 3$, july.

HUME, D. 1952. An enquiry concerning human understanding.

Chicago/London/Toronto: Encyclopedia Britannica, Inc.

HUME, D. 1978. A treatise of human nature, $2^{\text {nd }}$ ed. Oxford: Oxford University Press.

HUME, D. 1992. Diálogos sobre a religião natural, tradução br. de José Oscar de Almeida Marques. São Paulo: Martins Fontes.

HUME, D. 1998. An enquiry concerning the principles of morals. Oxford, New York: Oxford University Press.

KANT, I. 1952a. Kritik der Reinen Vernunft. Hamburg:Verlag von Felix Meiner.

KANT, I. 1952b. Kritik der Praktisch Vernunft. Hamburg:Verlag von Felix Meiner.

LEBRUN, G. 2000. O transcendental e sua imagem. In: ALLIEZ, É. (org.); coordenação da tradução de Ana Lúcia de Oliveira, Gilles Deleuze: uma vida filosófica. São Paulo: Ed. 34.

MACHADO, R. 1990. Deleuze e a Filosofia. Rio de Janeiro: Graal. MENGUE, Ph. 1994. Gilles Deleuze ou le Système du Multiple. Paris: Kimé.

ORLANDI, L. 2000. Antes do indivíduo (individuação em empirismo transcendental). In: O espírito das coisas, no prelo, cedido pelo autor.

PEIRCE, C.S. 1935. Three Types of Reasoning, Collected Papers of Charles Sanders Peirce, vol. v (Pragmatism and Pragmaticism), HATSHORNE, C. and WEISS, P. (eds.). Cambridge/Massachusets: The Belknap of Harvard University Press.

ZOURABICHVILI, F. 1994. Deleuze: Une Philosophie de l' Événement. Paris: PUF. 